\title{
BMJ Open A qualitative study of cancer care professionals' experiences of working with migrant patients from diverse cultural backgrounds
}

\author{
Alex Broom, ${ }^{1}$ Rhiannon Bree Parker, ${ }^{\oplus 1}$ Emma Kirby, ${ }^{1}$ Renata Kokanović, ${ }^{2,3}$ \\ Lisa Woodland, ${ }^{4}$ Zarnie Lwin, ${ }^{5,6}$ Eng-Siew Koh ${ }^{7,8}$
}

To cite: Broom A, Parker RB, Kirby E, et al. A qualitative study of cancer care professionals' experiences of working with migrant patients from diverse cultural backgrounds. BMJ Open 2019;9:e025956. doi:10.1136/ bmjopen-2018-025956

- Prepublication history and additional material for this paper are available online. To view these files, please visit the journal online (http://dx.doi. org/10.1136/bmjopen-2018025956).

Received 10 August 2018 Revised 21 November 2018 Accepted 24 January 2019

Check for updates

(C) Author(s) (or their employer(s)) 2019. Re-use permitted under CC BY-NC. No commercial re-use. See rights and permissions. Published by BMJ.

For numbered affiliations see end of article.

Correspondence to Professor Alex Broom; a.broom@unsw.edu.au and Dr Rhiannon Bree Parker; r.b.parker@unsw.edu.au

\section{ABSTRACT}

Objectives To improve the experiences of people from diverse cultural backgrounds, there has been an increased emphasis on strengthening cultural awareness and competence in healthcare contexts. The aim of this focusgroup based study was to explore how professionals in cancer care experience their encounters with migrant cancer patients with a focus on how they work with cultural diversity in their everyday practice, and the personal, interpersonal and institutional dimensions therein.

Design This paper draws on qualitative data from eight focus groups held in three local health districts in major metropolitan areas of Australia. Participants were health professionals $(n=57)$ working with migrants in cancer care, including multicultural community workers, allied health workers, doctors and nurses. Focus group discussions were audio recorded and transcribed in full. Data were analysed using the framework approach and supported by NVivo V.11 qualitative data analysis software.

Results Four findings were derived from the analysis:

(1) culture as merely one aspect of complex personhood;

(2) managing culture at the intersection of institutional, professional and personal values; (3) balancing professional values with patient values and beliefs, and building trust and respect; and (4) the importance of time and everyday relations for generating understanding and intimacy, and for achieving culturally competent care. Conclusions The findings reveal: how culture is often misconstrued as manageable in isolation; the importance of a renewed emphasis on culture as interpersonal and institutional in character; and the importance of prioritising the development of quality relationships requiring additional time and resource investments in migrant patients for enacting effective intercultural care.

\section{INTRODUCTION}

Therapeutic relationships between patients and healthcare professionals are critical to the quality of healthcare. ${ }^{1}$ Ethnocultural diversity has a considerable influence on the therapeutic encounter, communication and treatment trajectories. ${ }^{2}$ Moreover, the unique experiences, qualities and social positions
Strengths and limitations of this study

- Use of qualitative focus groups to elicit rich data on the dilemmas and challenges health professionals experience in working with cancer patients from diverse cultural backgrounds.

- Qualitative data may help highlight professional/institutional cultures and their relationship to individual beliefs, values and cultural practices.

- This study is exploratory in nature and experiences of working with migrant cancer patients may differ across settings/contexts.

of migrants have consistently been shown to have important implications for those living with cancer. ${ }^{3-7}$ In recent decades concepts such as 'cultural competence', 'cultural awareness', 'cultural sensitivity' and various other iterations have gained prominence within the healthcare systems of countries from the Organisation for Economic Co-operation and Development with a focus on improving quality in patient-professional relationships and promoting more effective therapeutic pathways. ${ }^{8}$ Such efforts have focused on more effectively managing cultural diversities. ${ }^{9}$ Although not without challenges, ${ }^{9} 10$ these (attempted) paradigm shifts have been productive in many respects. ${ }^{11}$ However, there has been an enduring tendency to focus on cultural diversity as individualised. For example, as about individual patient experiences, preferences or outcomes, rather than viewing working with culture as interactional (a product of relationships) and institutionally mediated (the outcome of divergent values between person and service provider). ${ }^{12}$ Here we focus on broadening understandings of the challenges of cultural diversity to include an emphasis on the interactions between people and between people and health systems. Focusing on cancer care, 
we examine how such ideas are balanced by health professionals who engage with migrants (including refugees and asylum seekers). While 'culture' defies exact definition due to its vast and varied nature, we use it broadly here to include norms, values, beliefs, objects and behaviours of particular social groups. ${ }^{14}$ In this study we focus on the experiences of professionals working with migrant patients in cancer care. For the purpose of the focus groups (and this article), migrant patients were defined as those born outside of Australia, and who identify as being from a culturally and linguistically diverse background. This includes ethnoculturally diverse people who travelled to Australia as migrants and does not include those ethnoculturally diverse people born in Australia (including, but not limited to, indigenous Australians).

\section{Shifting perspectives on 'culture' in care settings}

Despite the importance of integrating cultural diversity within care settings, both to improve biophysical outcomes and therapeutic relationships, ${ }^{13}$ approaches to working with cultural diversity in healthcare are varied, broad and often ambiguous. ${ }^{1415}$ They commonly focus on the individual patient as different rather than difference as emerging from interactions with others (be it other cultural backgrounds, or systems imbued with specific values). Whether focused on comprehension of advice, ${ }^{16}$ adherence to treatment ${ }^{17}$ or barriers to communication, ${ }^{18}$ the emphasis has been placed on the individual and in some respects potential individual deficits that need accommodating. ${ }^{19}$ Such models of cultural competence have been criticised for addressing culture-in-isolation; focusing on perceived cultural traits; ignoring diversity within 'culture'; engendering stereotype slippage and erasure of patient individuality; and ignoring the nexus of patient identity and the structural causes of health inequality. ${ }^{19-21}$ Yet little is known about how healthcare professionals' experience this evolving sphere of intercultural care-and the everyday dilemmas in achieving culturally competent care-a gap in knowledge that we begin to address in this study.

\section{Culture, complexity and moving beyond the individual}

In broader terms-beyond just the healthcare literature-models of cultural competency have gradually moved away from the logic of culture as categorical and reframed it as a constantly evolving interactional process that reflects the context and institutional environment as much as the features of the person/patient. ${ }^{141522}$ There is a growing emphasis on complex personhood that avoids the one-dimensional bracketing of person/patients. ${ }^{2}$ Personhood in this context includes issues of identity, preference, values and beliefs (on the part of patients, families and professionals), placing cultural dynamics as merely one, although important, factor in the broader interpersonal negotiation of care. Another important dimension to this complexity is the set of assumptions that underpin current and often idealised models of cancer care (eg, patient centredness). These assumptions may in fact sit in contrast to perceived or actual patient (cultural) beliefs and perspectives. For example, professional and institutional values around autonomy, agency, empowerment and individualised care-and as emphasised by the institutions of care and the treating clinicians who participated in this study-may further complicate the broader recognition and integration of cultural values and beliefs. Thus, in thinking about culture, we also need to consider values beyond patients themselves, including those of professionals, clinicians, institutions and families, and how these values shape care. ${ }^{23}$ In sum, how to meaningfully address cultural diversity is an ongoing project in medicine, and in oncology specifically. In this paper we report findings from a larger project focused on migrants' experiences of cancer. The research questions we ask here are, what are healthcare professionals' experiences of working with migrants with cancer, and what are their perspectives and views on the issues faced by migrants living with cancer?

\section{METHODS}

Drawing on interpretive approaches to research design, data collection and analysis, ${ }^{24}$ we used qualitative focus group discussions to explore healthcare professionals' experiences and perspectives on working with migrants in cancer care. Focus groups were chosen for the additional insight of group interaction in terms of consensus and/ or differing views, and the opportunity for clarification of opinions through debate which can expose previously concealed attitudes. ${ }^{25}$ Professionals in cancer or palliative care across hospital health districts participating in the study were approached and invited (via email or telephone) to participate by members of the research team (LW, E-SK, ZL). This included multicultural community workers within one local health district, and key representatives from several non-government organisations working within cancer care. Potential participants were given an information form outlining the aims of the study and the background of the researchers. A purposive sampling strategy was used to ensure representation from a range of organisations, professions and levels of experience, and coordinated through research team meetings. Participants had worked with migrants who, because of the services they were accessing (such as public hospitals and support services), were likely to have experienced vulnerability and required support (eg, assistance with language/interpreters, navigating the health system and social care support such as transport, managing appointments).

The focus group discussions were facilitated by EK (female) and $\mathrm{AB}$ (male), both university-based sociologists with extensive experience in qualitative research on the lived experience of cancer, and both from Anglo-Australian backgrounds. Their professional characteristics and backgrounds, explained to participants in focus groups, positioned them as sensitive and knowledgeable outsiders, insofar as they work outside of health services, 
but have knowledge and expertise in this area of practice. Facilitators were supported by a research team member who took notes during the focus groups and charted the order of speakers for ease of transcription, and by the other members of the research team through regular discussion and debriefing. A focus group discussion guide was developed following a review of the conceptual and empirical literature, and with input from research team members with various backgrounds and expertise (including sociology, oncology, community health and multicultural healthcare; see online supplementary files for guide questions). While this was used to broadly guide discussions, each discussion primarily flowed according to the priorities of the participants and interactional flow of each group. Discussions focused on the experience with and perceived impact of culture on care and the therapeutic encounter. Following ongoing concurrent analysis of the interviews, informed by the concept of saturation in qualitative research, ${ }^{26}$ the researchers agreed that no new themes on the topics of study were likely to be identified from further focus group discussions. The Standards for Reporting Qualitative Research checklist was used to ensure comprehensive reporting. ${ }^{27}$

\section{Patient and public involvement}

Patients and the public were not involved in the design of the study. The larger study is designed to explore and reveal patients' and their families' priorities, experiences and preferences; patients and their family caregivers will be recruited to share their experiences of living with cancer. Results will be disseminated to interested study participants in the form of an initial one-to-two-page synopsis. Any reports or publications are also made available to participants upon request.

\section{Analysis}

Data from the focus groups were professionally transcribed verbatim and entered into NVivo V.11. In line with sociological interpretive traditions, our approach to analysis focused on reaching a nuanced understanding of the range of perspectives within systems of beliefs and life experiences more broadly. ${ }^{24}$ We employed the framework approach, a flexible tool for qualitative approaches that aims to generate themes in multidisciplinary health research, ${ }^{28}$ using NVivo V.11 software to systematically analyse the transcripts. ${ }^{29}$ We employed the following steps: (1) familiarisation: researchers reviewed the transcripts. (2) Identification of framework: key themes were identified around which the data were organised. (3) Indexing: application of themes to text. This involved labelling and arranging each text excerpt, word, term or research note related to each participant and/or group transcript. This produced several lists including data and notes from several participants according to each theme and group. (4) Charting: headings and subheadings were used to build a picture of the data as a whole. Each thematic 'index' was discussed by three research team members, with Authors $\mathrm{AB}$ and RP leading the development of

\begin{tabular}{ll}
\hline \multicolumn{2}{l}{ Table 1 Participant demographics } \\
\hline Characteristics & No. (\%) \\
\hline Gender & \\
\hline Female & $47(82.5)$ \\
\hline Male & $10(17.5)$ \\
\hline Age & \\
\hline $18-29$ & 4 \\
\hline $30-39$ & 17 \\
$40-49$ & 15 \\
\hline $50-59$ & 14 \\
\hline $60+$ & 6 \\
\hline Years of experience & \\
\hline Mean & 15.6 \\
\hline Range & $1-40$ \\
\hline Place of birth & \\
\hline Outside Australia & $31(54.4)$ \\
\hline Australia & $26(45.6)$ \\
\hline Identified as migrant & $14(24.6)$ \\
\hline Occupation & \\
\hline Allied health & $26(45.6)$ \\
\hline Medical practitioner & $13(22.8)$ \\
\hline Nurse & $10(17.6)$ \\
\hline Community worker & $8(14)$ \\
\hline
\end{tabular}

summaries for each thematic area: one 'overall' summary, along with one summary for each focus group. (5) Mapping and interpretation: associations were clarified, and explanations developed. This involved finding associations between and within themes and moving towards and developing explanations for the findings in line with our research aims. ${ }^{28}$ Independent coding of the data was provided initially by members of the research team $(\mathrm{AB}$, $\mathrm{RP}$ ) and was cross-checked to facilitate the development of themes (EK), moving towards an overall interpretation of the data. Analytic rigour was enhanced by searching for negative, atypical and conflicting or contradicting cases in coding and theme development. ${ }^{25} 2930$ Inter-rater reliability was ensured by integrating research team members in the final analysis, including two cancer specialists.

\section{RESULTS}

We facilitated focus groups at three hospitals in two states in Australia. Five focus groups were conducted in New South Wales and three in Queensland. Fifty-seven individuals (see table 1 for an overview of participant characteristics) provided informed consent in writing to participate in focus groups throughout 2017. The focus groups were organised according to participating organisations, with some including several professional groups, while others included single professions: (FG1) allied health workers \& nurses; (FG2) medical staff; (FG3) multicultural 
Table 2 Indicative quotations: culture as only one aspect of patient complexity

\begin{tabular}{|c|c|}
\hline Participants & Quote \\
\hline $\begin{array}{l}\text { P18 (female, } \\
\text { counsellor) }\end{array}$ & $\begin{array}{l}\text { So, for me now, it's looking at, "Well, what were those cultural expectations? To what degree does my } \\
\text { client subscribe to them?" She's actually from the same cultural background, and so it really becomes } \\
\text { about families, about individuation, about what is community and then what's the intersection between } \\
\text { all of them [...] if we heard this particular cultural expectation we'd all go, "Oh yes, we know that of that } \\
\text { culture". But actually, it's not working for this family who are actually all from the same culture (FG3). }\end{array}$ \\
\hline $\begin{array}{l}\text { P18 (female, } \\
\text { counsellor) }\end{array}$ & $\begin{array}{l}\text { I think there is no doubt that there's always a tension at an ethical level between providing client-centred } \\
\text { care for an individual and being able to meet greater service demands and being able to capture a } \\
\text { greater group of people. I think that's a reality. Unfortunately, I think it gets used as an excuse for not } \\
\text { providing good quality client-centred care and I suppose part of what we've been trying to even define } \\
\text { today is what is client-centred care? Is it looking at the individual or is it looking at the individual within } \\
\text { family and then what are the confidentiality issues, the privacy issues, the respect of culture issues that } \\
\text { come up there? (FG3). }\end{array}$ \\
\hline $\begin{array}{l}\text { P57 (male, medical } \\
\text { practitioner) }\end{array}$ & $\begin{array}{l}\text { In very complex care scenarios, you almost need people who subspecialise in (cultural competence) in } \\
\text { a way because it's almost too much to assume everyone maintains the competency you need to have to } \\
\text { look after these patients, in a way. There needs to be a group of people who have quick resources, the } \\
\text { extra time, and they're actually protected from having to treat them in a quick way. That's the only way } \\
\text { it's going to be done properly (FG8). }\end{array}$ \\
\hline $\begin{array}{l}\text { P30 (female, nurse) } \\
\text { P28 (female, nurse) }\end{array}$ & $\begin{array}{l}\text { P30: And some of the challenges around new diagnosis, depending on certain cultures, you can't } \\
\text { generalise, but some believe that cancer is contagious ... No matter what you say it's - } \\
\text { P28: It's ingrained } \\
\text { P30: - it's ingrained to shift that and that can be very hard to observe when you know that it can be a } \\
\text { better process. Yeah, but it's so ingrained (FG4). }\end{array}$ \\
\hline $\begin{array}{l}\text { P38 (female, clinical } \\
\text { psychologist) }\end{array}$ & $\begin{array}{l}\text { Because it's part of the mix. I mean, you're presenting that as though it's a dichotomy, but it's not a } \\
\text { dichotomy. It's just part of the complexity, and if the cultural aspect of that person is more predominant, } \\
\text { then that's going to be more of that complexity for that person. If there are other things that come into } \\
\text { the mix and if you've got low SES, isolation, depression, and all that sort of thing, then you're taking } \\
\text { that all into account. So I don't know that it's an eitherlor kind of thing. I think it's definitely important, } \\
\text { but it's not always the most important thing. You've just got to allow for that diversity. I agree with you. I } \\
\text { think a lot of the things that we look at as far as how we're going to respond better to a culturally diverse } \\
\text { population, we should be thinking about for everybody. So some of the things that we can learn from } \\
\text { doing that better we should be able to move onto other people as well (FG6). }\end{array}$ \\
\hline
\end{tabular}

community/allied health workers; (FG4) nursing and social work hospital staff; (FG5) multicultural community workers; (FG6) allied health workers; (FG7) nursing staff; and (FG8) medical staff. Focus groups were conducted by $\mathrm{EK}$ and $\mathrm{AB}$, lasted 45-135 min (median: $60 \mathrm{~min}$ ) and were audio recorded. Medical staff included representation from medical and radiation oncology, haematology, general and emergency medicine and palliative care. Allied health staff included representation from social work, pharmacy, psychology, physiotherapy, dietetics, radiation therapy and speech pathology. Multicultural community workers included case managers, program managers, community development workers, multicultural health workers, counsellors, pastoral care workers and primary care and prevention project officers.

\section{Culture as only one aspect of patient complexity}

Within the focus groups, culture was acknowledged as integral to patient identities and recognition of culture was frequently discussed as critical to quality caring relationships (indicative quotations are shown in table 2 ). The uniqueness of each patient was stressed across all eight focus groups, and discussions revealed that the operationalisation of cultural competence in professional-patient interactions was challenging. In particular, all groups offered diverse but consistent accounts of the 'traps' of treating culture as fixed or discrete and the implications of this for treating the patient. These discussions revealed a series of professional tensions regarding resolving the particularities of the individual person and the generalities of 'their culture', as captured by P18, FG3 (table 2). The focus group discussions included various pragmatic attempts and solutions to such tensions or challenges. For example, several participants from medical perspectives discussed delegating complex cases to allied health or multicultural healthcare workers, given the time and resources needed to work with migrant patients. Yet this was challenged by those in the groups who viewed this as relegating working with cultural difference to non-medical specialists, which would not improve relationships between providers and patients.

Although there was widespread consensus that culture was experienced differently in each person, participants found this difficult to translate into everyday practice. Thus, there was recognition of culture as one aspect of the person (see the interaction between P30 and P28, table 2). Yet treating a patient as a unique person was often 
Table 3 Indicative quotations: the interplay of institutional, professional and personal values

\begin{tabular}{|c|c|}
\hline Participants & Quote \\
\hline $\begin{array}{l}\text { P31 (female, nurse) } \\
\text { P30 (female, nurse) } \\
\text { P28 (female, nurse) }\end{array}$ & $\begin{array}{l}\text { P31: The patient has to be able to say, "I have cancer. I'm having treatment. I'm having } \\
\text { chemotherapy for my cancer". So I'm pretty strict about that [...] It's very important, } \\
\text { principally, for the patient to understand that they may have a life-limiting illness and that } \\
\text { they're actually aware. I just don't think it's a safe practice to be vague about the fact that you } \\
\text { actually have cancer. I just do not think it's safe at all. It causes a feeling of tension between } \\
\text { the professional people and the patients [...] } \\
\text { P30: But, also, what have they consented to if they don't know? } \\
\text { P31: That's exactly right. } \\
\text { P28: They don't understand (FG4). }\end{array}$ \\
\hline $\begin{array}{l}\text { P11 (female, medical } \\
\text { practitioner) }\end{array}$ & $\begin{array}{l}\text { I think the western medicine concept of patient autonomy and open disclosure, we still try } \\
\text { and stick to that (FG2). }\end{array}$ \\
\hline $\begin{array}{l}\text { P29 (female, social worker) } \\
\text { P30 (female, nurse) }\end{array}$ & $\begin{array}{l}\text { P29: So we have to look at how can we meet people's needs. Even looking when we're trying } \\
\text { to reflect on who's actually using our service. So we had a really good talk with one of the } \\
\text { diversity health workers, a Chinese diversity health worker, to look at who's engaging and } \\
\text { why they might not be, what can we do [...] and it's interesting about who we're servicing } \\
\text { and why. } \\
\text { P30: But also, if we don't meet the cultural needs while they're in hospital and try to box } \\
\text { them into our western way of thinking, as soon as they leave the building they're going to } \\
\text { slide back under the radar with no supports and go, "Well I'm not doing it that way". } \\
\text { P29: Yep. } \\
\text { P30: And we've done them no service whatsoever- } \\
\text { P29: Yeah. } \\
\text { P30: - and they could end up compromised without the appropriate supports in the } \\
\text { community (FG4). }\end{array}$ \\
\hline P2 (female, physiotherapist) & $\begin{array}{l}\text { I'm not going to go up and say, "You've got cancer", but if the patient asks me, "What is } \\
\text { wrong with me?" then I have a professional and a medicolegal responsibility to actually tell } \\
\text { them knowing full well that the patient's probably never going to ask me or have already kind } \\
\text { of worked it out themselves. But it's that really internal moral and ethical, "Where do I stand } \\
\text { in this in terms of my professionalism?" (FG1). }\end{array}$ \\
\hline
\end{tabular}

considered unrealistic in everyday practice given resource and institutional constraints, especially where 'culture', perceived as language difficulties or divergent beliefs, was viewed as an impediment to expedient care. There was thus slippage in the discussions towards framing culture as a barrier despite theoretical recognition of culture as complex and present in every person. This resulted in 'culture' being individualised, used to articulate difference, and present in patients but not professionals. This was linked to the interplay of professional, institutional and patient values, which we address below.

\section{The interplay of professional, institutional and patient values}

As shown in the indicative quotations in table 3 , the focus groups discussed the additive assumptions of health professionals themselves and how they were embedded in institutional and biomedical cultural values. The culture of professionals and institutions was often framed by participants as a concealed dimension of the broader 'cultural' dynamics of care. For example, we heard frequent discussion of how biomedical priorities (the prioritisation of the physical and biological aspects of the patient) and institutional policies and practices dominated therapeutic approaches and professional-patient relationships. Moreover, significant emphasis was placed within group discussions on imparting biomedical values to the patient. Such priorities and associated values were positioned as 'western' approaches (We use 'western approaches' rhetorically as it was used within focus groups, while acknowledging that this is an umbrella notion with a highly differentiated set of practices) to illness and care and were often assumed to be fixed, acultural and unyielding. A key example (see table 3) was the discussion around what participants perceived as 'western' ideas about autonomy, full disclosure, informed consent or individual choice and the difficulties in operationalising cultural sensitivity with particular migrant groups.

Across the focus groups, the belief systems of both the patient and the participant were discussed as driving participants' own dispositions. Thus, cultural competence was ultimately considered interpersonal where 
one's own values needed to be balanced and acknowledged alongside those of the patient. There was tension within the focus groups (see table 3) between 'correcting' migrant patient perspectives to be in line with what was biomedically prioritised and/or institutionally approved and recognising the importance of meaningfully integrating patient values into care. As a result, as shown in the group interactions, managing culture emerged as a series of tensions between values, and shaped by institutionalised values that are embedded in 'medicolegal responsibility' and 'professionalism' (see table 3). This interplay of professional, institutional and personal values as articulated within the context of 'managing' the cultural specificities of the person is highlighted for example by P2, FG1 (table 3).

A balancing act: values, beliefs, trust and respect in everyday practice

A consistent discussion point across the focus groups was the need to balance respect for patients' cultural beliefs and practices with professional values. For example, P51 discussed patient values as 'in conflict with our own ethics about autonomy' and as producing 'internal conflict' (table 4). Reconciling the competing priorities of recognition of culture and delivery of ethical care was an ever present and pressing concern, articulated, for example, through repeated use of balance metaphors (see table 4). Examples of attempts to balance conflicts between person-centredness and cultural competence revealed the potential disjunctions between the two, with P13 providing the example of 'not using the word cancer'.

There was broad recognition across the groups that a failure to recognise or balance potentially competing professional, institutional and patient values could lead to rigidity, barriers to trust and respect and 'set up an adversarial relationship'. Several groups discussed responding to such complex scenarios by adopting a 'back to basics' approach founded on respect (see P8, FG1, table 4). There were several instances of compromise-essentially

Table 4 Indicative quotations: a balancing act: values, beliefs, trust and respect in everyday practice

\section{Participants}

P51 (female, medical practitioner)

P11 (female, medical practitioner)

P8 (female, nurse)

P9 (female, speech pathologist)

P13 (male, medical practitioner)

P41 (female, social worker)

P8 (female, nurse)

P2 (female, physiotherapist)

P15 (female, medical practitioner)

P48 (female, nurse)

\section{Quote}

So, we get taught a lot in terms of the indigenous cultural sensitivities about discussing it with the right people, but it's very much in conflict with our own ethics about autonomy and we can't really override a patient's autonomy. It's really important that their wishes are being granted. So, it's often this internal conflict for us and also trying to do the right thing by the patient (FG8).

... toe that line (FG2).

It's all about crossing that bridge and make sure you don't fall (FG1). ... treading a fine line (FG1).

I think you have to be culturally sensitive, but you also have to disclose information in an honest, open manner, and that's the first step of establishing, I guess, trust. Sometimes it can lead to families being very angry, but there may be ways of discussing cancer, not using the word cancer, but explaining to them what cancer means more than anything. That's generally how a lot of us are trying to get around that (FG2).

I think what you were saying before about a level of distrust, there's a lot of that as well. Because revealing what (alternative medicine) you're taking has the danger of being told not to use it and perhaps, because it's very much a medical model here, they may not feel there's a sympathy towards that perspective either. So that unfortunately then can set up an adversarial relationship where they're feeling that their beliefs aren't being respected and their way of managing health is not being respected and then the gap gets wider (FG6).

P8: ... respecting what they want to know, not what you think that they should know. P2: Yeah, get rid of that maternalistic stuff.

P8: Exactly. It's like, I know that you want to do your job, but, really, are you doing your job if you're distressing them? No, you're not (FG1).

... he's getting something and they're happy with that, and I put clear boundaries of, "But if he becomes symptomatic and it makes him sick I will need to stop it because I don't want to hurt him". But sometimes you just need to let go of what you think is medically most appropriate, as long as you're not causing harm (FG2).

I think you've got to acknowledge and respect those patients for their beliefs and cultures. In my experience and the way l've been trained is to try and respect those patients, but then balance it with, "Well at the moment you're receiving this special chemo that will help. You might need to lay off your complementary medicine just while you're receiving the treatment because we're not sure how it will make you feel". So try and let them know that it has a place, but maybe at that stage of their treatment it's not necessarily the right thing (FG7). 
Table 5 Indicative quotations: everyday relations for gaining understanding, intimacy and recognition

\begin{tabular}{l} 
Participants \\
practitioner) \\
\hline (male, medical \\
\hline
\end{tabular}

P57 (male, medical practitioner)

P53 (male, medical

practitioner)

\section{Quote}

I've found that there's often cultural contracts which we don't understand. It takes a long time to understand in terms of the process that an individual will go through in making a decision. Even if we give them all the information that's available in terms of what options are there, they'll make a decision that we just struggle to really comprehend [...] Where I was working we had to send (patients) to the different islands or the big city for further investigations and treatment and they said, "No, not a chance, because I'm willing to die at home because I need to die on my own island. Even if I could get treatment that could prolong my life, save my life, the risk of dying away from home is too much of an issue", based on her beliefs and so she would just forego medical care as a result of that. And it took a long time That took a week to get to that point of understanding, and even some of the local doctors, they were from different islands, different cultures in the same country, so they couldn't really grapple with it. I suppose that's that lack of understanding which is sometimes a barrier to us knowing why a decision has been made (FG8).

P57: I would say the thing I try and do is often if I've got to have a very complex, long discussion that I would normally do in an hour, I would just try and book three appointments...

P53: I think it brings to the fore something that we don't understand very well, and to use an example, (the doctor) wants to transplant somebody, "So we're going to do this and we're going to do that and we're going to get this from there and then we're going to do that and these are the things that can happen, and that's the mechanics of it", and that's all the patient needs to know from a technical perspective. So what's the other 2 hours? That's (the doctor), the person, relating to the patient as a person and that trust builds up and that's all (FG8).

\begin{tabular}{|c|c|}
\hline P8 (female, nurse) & $\begin{array}{l}\text { I don't think there's anything wrong in acknowledging and saying, "Look, I understand this is part } \\
\text { of your culture", or whatever the case may be, but just saying, "Look, it also won't hurt if I run } \\
\text { this by these people because sometimes what you're doing can actually cause problems to the } \\
\text { other treatment they're receiving", and more often than not, people will say, "I didn't realise that" } \\
\text { (FG1). }\end{array}$ \\
\hline P36 (female, dietitian): & $\begin{array}{l}\text { I guess it's acknowledging that that's an important value system for them and that we're certainly } \\
\text { not against that, but just trying to open or build that rapport (FG6). }\end{array}$ \\
\hline
\end{tabular}

bargaining with patients over, for example, the use of alternative medicines - that provided a resolution for both parties, acknowledging the distance between respective sets of values (see P15, FG2, table 4). From the perspective of participants, such compromises were framed as both genuine attempts to foster mutual respect, and practical compromises to improve treatment compliance.

\section{Everyday relations for gaining understanding, intimacy and recognition}

The final theme we focus our attention on is the significance of concealed and/or often unacknowledged 'everyday encounters' as the key to quality intercultural care (indicative quotations shown in table 5). We refer here to participant accounts of the potential in informal exchanges for facilitating individual and reciprocal intercultural understanding and breaking down barriers. For example, P57 and P53 (FG8) discussed the significance of informal conversations with their migrant patients to 'relating to the patient as a person' and building trust. The groups often discussed the complexity and confusion they felt in attempting to understand, or even be privy to, cultural values that differed from their own. Participants frequently flagged their lack of understanding of cultural contracts and values, reflecting the ontological barriersdifferences in values and beliefs-that potentially exist between professional and patient. The importance of time and relationship was emphasised by participants in this context as crucial.

Participants repeatedly mentioned the importance of time invested in the therapeutic relationship with migrants, and the group discussions raised a range of nuanced perspectives. This was captured in P49's talk of ' 2 am chats' 
in the hospital between nurse and patient (see table 5). The focus groups described the investment in relationships that allowed for discussion and identification of concealed cultural values and enabled improved understanding and intimacies in the management of divergent beliefs and experiences. The counterscenario was commonly talked about-clinicians withdrawing from relationships with migrant patients (particularly those with language difficulties), instilling cultural difference as interpersonal barrier, representing a potentially damaging cycle for migrant cancer patients and their clinicians.

For participants wishing to engage in dialogue with patients there were efforts to remain open towards cultural diversity while simultaneously supporting their own cultural position. Such attempts to respect and understand cultural differences through everyday interactions were talked about as improving participants' own acceptance of and comfort with these differences.

Efforts which aimed to promote mutual respect and understanding were discussed as enabling better communication and trust and reducing participants' bias towards particular cultural practices in cancer care. Ultimately, mundane acts such as spending time with and maintaining respect for each patient-objectives professionals have for any patient - uncovered concealed cultural values and helped develop an understanding of the person.

\section{DISCUSSION}

In this article we have explored some of the undulations of working with migrant patients with cancer as experienced by several groups of healthcare professionals. The findings reveal the importance of an emphasis on complex personhood, culture as intersubjective (as existing between people) and the role of everyday encounters in facilitating productive therapeutic encounters. Our research builds on existing important work on better understanding cultural dynamics in healthcare settings, ${ }^{23}$ to add further insight into how 'culture' is being managed in practice in all its institutional, interpersonal and personal complexities.

The core theme derived from the analysis was complex personhood although it was not always articulated in those specific terms. This was not necessarily about the many aspects of patient biographies such as dimensions of gender, class or ethnicity. Rather it was about the layers of aspects of the person, and integration of these aspects into care. For example, participants perceived that, for some patients, the relative importance of family values or individual idiosyncrasies may have been more central to decision making than specific cultural practices. This was positioned as a problem for healthcare professionals in terms of treating culture in isolation from other aspects of the person. This idea captured what is in some respects the Catch-22 of cultural awareness-that healthcare professionals should learn about and be sensitive to culture but that this sensitivity could lead to a lack of recognition of the individuality of the patient and a reduction of personhood to cultural abstractions. The groups provided insight into managing this dilemma in everyday oncological practice.

The groups also articulated 'culture' as a complex interplay between the personal, professional and institutional. This centred on the groups' identification of the interplay of values, beliefs and practices across stakeholders and between individuals and institutions/professions. For example, participants at times viewed the biomedical way of thinking as being at odds with their perceptions of migrant values, views or ways of thinking. ${ }^{31} 32$ This posed an important question for these professionals: how to respect and treat the migrant patient with cancer with dignity while maintaining at least some norms of practice within scientised biomedical practice (eg, 'best' courses of treatment, technologically advanced care with a scientific evidence base, and expedient treatment ${ }^{19}$ ). While there was no consensus across participants on how to reconcile such disjunctions, there was a recognition of often countervailing forces across these spheres. In line with previous work which has highlighted the relationship between ethical practice and cultural competence, ${ }^{19} 20$ the participants in our study routinely discussed concepts of ethics or professionalism as juxtaposed with those of belief and practice. This raised both ongoing complexities and revealed the importance of viewing 'cultural competence' as operating at the nexus of the personal, professional and institutional, regardless of whether there is agreement on how to work with it. These findings thus add to existing work which emphasises a broadening out of cultural competence and awareness to recognise the contributions that a wider range of actors make to the context of care. ${ }^{6} 101433$

Finally, our findings indicate the critical nature of everyday, 'mundane' interactions (such as informal conversations and longer consultations) for addressing distance or disjunctions between healthcare providers and their patients. The considerable risk with migrant patients was that differences effectively reduced time committed to everyday conversations, adding an additional layer of distance and potential misunderstandings or disjunctions. In combination with the importance of awareness of participants' own biographies, the focus groups emphasised the potency of engaging in the seemingly mundane act of spending time with patients for fostering mutual understanding and respect. ${ }^{34}{ }^{35}$ This helped professionals facilitate a better understanding of the layering of complexity outlined above, enabled them to see their own contributions to the production of 'otherness', and to reconcile some disjunctions between institutional demands, professional ethics and individualised preference. $^{183336}$

\section{Implications}

The findings of this study have several practical implications. First, it is important that there be a renewed focus within cultural competence training on encouraging health professionals to routinely consider and reflect on the ways that each clinical encounter is shaped by patient, clinician and institution. This will improve awareness that these encounters as shaped by all stakeholders and not 
just the difference of patients. In line with the findings of Kumagai and Lypson, ${ }^{33}$ cultural competency requires a critical awareness of both self and others: encouraging reflection on the ways by which all parties bring their own values to a clinical encounter may promote such everyday encounters as holding the potential to be transformative. Future research is needed to examine how healthcare services can provide for and encourage these often unacknowledged and underappreciated approaches to care and interaction with patients and their families. Moreover, research focused on uncovering the benefits of providing professionals with additional time and resources to achieve positive outcomes with migrant patients is especially important given the consensus around the limiting potential of resource constraints within this study.

\section{Limitations}

This study is not without limitations. Our participants were recruited from three health districts in two Australian cities. As such, our findings may not be indicative of the experiences of healthcare professionals elsewhere. Participants also self-selected by volunteering and were from a wide range of cultural backgrounds with varying levels of experience in working with migrant patients. Finally, we note that our findings above, and the focus group discussions themselves, are situated perspectives and represent only one facet of the broader story of illness and care. Future research is needed to add considerations of patient family and community perspectives.

\section{CONCLUSION}

This study offers new challenges to, and builds upon, existing concepts and models of care (eg, cultural awareness or sensitivity) and reveals important connections between often opaque dynamics in the ongoing construction of culture and difference. It provides a timely reminder of the importance of resisting enduring and new forms of reductionism (however 'well meaning' they might be), but it is also instructive for reconceptualising culture as much greater than simply the person; rather, as interpersonally and institutionally produced. In this respect, it indicates a need to treat culture as one facet of complex personhood, as operating between patients and clinicians, and between people and institutions.

\section{Author affiliations}

${ }^{1}$ Centre for Social Research in Health, Faculty of Arts and Social Sciences, University of New South Wales, Sydney, New South Wales, Australia

${ }^{2}$ Social and Global Studies Centre, RMIT University, Melbourne, Victoria, Australia

${ }^{3}$ Monash Centre for Health Research and Innovation, Monash University, Melbourne, Victoria, Australia

${ }^{4}$ Multicultural Health Service, South Eastern Sydney Local Health District, Sydney, New South Wales, Australia

${ }^{5}$ Faculty of Medicine, University of Queensland, Brisbane, Queensland, Australia ${ }^{6}$ Department of Medical Oncology, Royal Brisbane and Women's Hospital, Brisbane, Queensland, Australia

${ }^{7}$ South Western Sydney Clinical School, University of New South Wales, Sydney, New South Wales, Australia
${ }^{8}$ Department of Radiation Oncology, Liverpool Hospital, Sydney, New South Wales, Australia

Contributors The project was designed and developed by AB, EK, RK, LW, ZL and E-SK. Data were collected by EK and AB. Data analysis was led by AB, RP and EK with input from RK, LW, ZL and E-SK. All authors contributed to the drafting and revising of the manuscript and approved the final version of the manuscript.

Funding This work was supported by the Australian Research Council Linkage Grant LP160100100.

Competing interests None declared.

Patient consent for publication Not required.

Ethics approval Royal Brisbane \& Women's Hospital Human Research Ethics Committee HREC/16/QRBW/296.

Provenance and peer review Not commissioned; externally peer reviewed. Data sharing statement № additional unpublished data are available.

Open access This is an open access article distributed in accordance with the Creative Commons Attribution Non Commercial (CC BY-NC 4.0) license, which permits others to distribute, remix, adapt, build upon this work non-commercially, and license their derivative works on different terms, provided the original work is properly cited, appropriate credit is given, any changes made indicated, and the use is non-commercial. See: http://creativecommons.org/licenses/by-nc/4.0/.

\section{REFERENCES}

1. De Vries AM, de Roten Y, Meystre C, et al. Clinician characteristics, communication, and patient outcome in oncology: a systematic review. Psychooncology 2014;23:375-81.

2. Pinder RJ, Ferguson J, Møller H. Minority ethnicity patient satisfaction and experience. BMJ Open 2016;6:e011938.

3. Butow PN, Bell ML, Aldridge LJ, et al. Unmet needs in immigrant cancer survivors: a cross-sectional population-based study. Support Care Cancer 2013;21:2509-20.

4. Goldstein D, Bell ML, Butow PN, et al. Immigrants' perceptions of the quality of their cancer care: an Australian comparative study. Ann Oncol 2014;25:1643-9.

5. Kokanovic R, Manderson L. Exploring doctor-patient communication in immigrant Australians with type 2 diabetes: a qualitative study. $J$ Gen Intern Med 2007;22:459-63.

6. Lionis C, Papadakaki M, Saridaki A, et al. Engaging migrants and other stakeholders to improve communication in cross-cultural consultation in primary care: a theoretically informed participatory study. BMJ Open 2016;6:e010822.

7. Sze M, Butow P, Bell M, et al. Migrant health in cancer: outcome disparities and the determinant role of migrant-specific variables. Oncologist 2015;20:523-31.

8. Renzaho AM, Romios P, Crock C, et al. The effectiveness of cultural competence programs in ethnic minority patient-centered health care--a systematic review of the literature. Int J Qual Health Care 2013;25:261-9.

9. Thackrah RD, Thompson SC. Refining the concept of cultural competence: building on decades of progress. Med J Aust 2013;199:35-8.

10. Jenks AC. From "lists of traits" to "open-mindedness": emerging issues in cultural competence education. Cult Med Psychiatry 2011;35:209-35.

11. Truong M, Paradies $\mathrm{Y}$, Priest $\mathrm{N}$. Interventions to improve cultural competency in healthcare: a systematic review of reviews. BMC Health Serv Res 2014;14:99.

12. van Eechoud IJ, Grypdonck M, Beeckman D, et al. Oncology health workers' views and experiences on caring for ethnic minority patients: A mixed method systematic review. Int J Nurs Stud 2016;53:379-98.

13. Broom A, Good P, Kirby E, et al. Negotiating palliative care in the context of culturally and linguistically diverse patients. Intern Med J 2013;43:1043-6.

14. Azzopardi C, McNeill T. From cultural competence to cultural consciousness: transitioning to a critical approach to working across differences in social work. J Ethn Cult Divers Soc Work 2016;25:282-99.

15. Betancourt JR, Green AR, Carrillo JE, et al. Defining cultural competence: a practical framework for addressing racial/ ethnic disparities in health and health care. Public Health Rep 2003;118:293-302. 
16. Ingram RR. Using Campinha- Bacote's process of cultural competence model to examine the relationship between health literacy and cultural competence. J Adv Nurs 2012;68:695-704

17. Ohana S, Mash R. Physician and patient perceptions of cultural competency and medical compliance. Health Educ Res 2015;30:923-34.

18. Surbone A. Cultural aspects of communication in cancer care. Support Care Cancer 2008;16:235-40.

19. Muaygil RA. From paternalistic to patronizing: How cultural competence can be ethically problematic. HEC Forum 2018;30:13-29.

20. Jeffery D, Nelson J. 'What Are We To Do About Difference?': Race, culture and the ethical encounter. Ethics and Social Welfare 2011;5:247-65.

21. Kirmayer LJ. Rethinking cultural competence. Transcult Psychiatry 2012;49:149-64

22. Ahmed S, Siad FM, Manalili K, et al. How to measure cultural competence when evaluating patient-centred care: a scoping review. BMJ Open 2018;8:e021525.

23. Schrank B, Rumpold T, Amering M, et al. Pushing boundariesculture-sensitive care in oncology and palliative care: a qualitative study. Psychooncology 2017;26:763-9.

24. Charmaz K. 'Discovering' chronic illness: using grounded theory. Soc Sci Med 1990;30:1161-72.

25. Fitzpatrick R, Boulton M. Qualitative research in health care: I. The scope and validity of methods. J Eval Clin Pract 1996;2:123-30.

26. Malterud K, Siersma VD, Guassora AD. Sample size in qualitative interview studies. Qual Health Res 2016;26:1753-60.
27. O'Brien BC, Harris IB, Beckman TJ, et al. Standards for reporting qualitative research: a synthesis of recommendations. Acad Med 2014;89:1245-51.

28. Gale NK, Heath G, Cameron E, et al. Using the framework method for the analysis of qualitative data in multi-disciplinary health research. BMC Med Res Methodol 2013;13:117.

29 Pope C, Ziebland S, Mays N, et al. Analysing qualitative data. In: Pope C, Mays N, eds. Qualitative research in health care. 3rd ed. Oxford: Blackwell Publishing, 2006:63-81.

30. Ezzy D. Qualitative analysis. Australia: Allen and Unwin, 2013.

31. Tervalon M, Murray-García J. Cultural humility versus cultural competence: a critical distinction in defining physician training outcomes in multicultural education. J Health Care Poor Underserved 1998;9:117-25

32. Kokanovic R, May C, Dowrick $C$, et al. Negotiations of distress between east timorese and vietnamese refugees and their family doctors in Melbourne. Sociol Health IIIn 2010;32:511-27.

33. Kumagai AK, Lypson ML. Beyond cultural competence: critical consciousness, social justice, and multicultural education. Acad Med 2009;84:782-7.

34. Appiah A. Cosmopolitanism: Ethics in a world of strangers. London: Penguin, 2007.

35. Watts KJ, Meiser B, Zilliacus E, et al. Communicating with patients from minority backgrounds: individual challenges experienced by oncology health professionals. Eur J Oncol Nurs 2017;26-83-90.

36. Saha S, Beach MC, Cooper LA. Patient centeredness, cultural competence and healthcare quality. J Natl Med Assoc 2008; $100: 1275-85$ 